\title{
Examining the impact of introducing ICD-MM on observed trends in maternal mortality rates in the UK 2003-13
}

Marian Knight ${ }^{*}$ DD, Manisha Nair ${ }^{1}$, Peter Brocklehurst ${ }^{2}$, Sara Kenyon ${ }^{3}$, James Neilson ${ }^{4}$, Judy Shakespeare ${ }^{1}$, Derek Tuffnell ${ }^{5}$, Jennifer J. Kurinczuk ${ }^{1}$ on behalf of the MBRRACE-UK collaboration

\begin{abstract}
Background: The causes of maternal death are now classified internationally according to ICD-MM. One significant change with the introduction of ICD-MM in 2012 was the reclassification of maternal suicide from the indirect group to the direct group. This has led to concerns about the impact of this reclassification on calculated mortality rates. The aim of this analysis was to examine the trends in maternal deaths in the UK over the past 10 years, and to investigate the impact of reclassification using ICD-MM on the observed rates.
\end{abstract}

Methods: Data about all maternal deaths between 2003-13 in the UK were included in this analysis. Data about maternal deaths occurring prior to 2009 were obtained from previously published reports. The deaths of women from 2009-13 during or after pregnancy were identified through the MBRRACE-UK Confidential Enquiry into Maternal Deaths. The underlying causes of maternal death were reclassified from a disease-based system to ICDMM. Maternal mortality rates with $95 \%$ confidence intervals were calculated using national data on the number of maternities as the denominator. Rate ratios with $95 \% \mathrm{Cl}$ were calculated to compare the change in rates of maternal death as per ICD-MM relative to the old classification system.

Results: There was a decrease in the maternal death rate between 2003-05 and 2011-13 (rate ratio (RR) 0.65; $95 \%$ Cl 0.54-0.77 comparing 2003-5 with 2011-13; $p=0.005$ for trend over time). The direct maternal death rate calculated using the old classification decreased with a RR of 0.47 (95\% Cl 0.34-0.63) when comparing 2011-13 with 2003-05; $p=0.005$ for trend over time. Reclassification using ICD-MM made little material difference to the observed trend in direct maternal death rates, $\mathrm{RR}=0.51$ (95\% Cl 0.39-0.68) when comparing 2003-5 with 2011-13; $p=0.005$ for trend over time.

Conclusions: The impact of reclassifying maternal deaths according to ICD-MM in the UK was minimal. However, such reclassification raises awareness of maternal suicides and hence is the first step to actions to prevent women dying by suicide in the future. Recognising and acknowledging these women's deaths is more important than concerns over the impact reclassification using ICD-MM might have on reported maternal death rates.

Keywords: Maternal mortality, International classification of diseases, ICD-MM, Confidential enquiry

\footnotetext{
* Correspondence: marian.knight@npeu.ox.ac.uk

${ }^{1}$ National Perinatal Epidemiology Unit, Nuffield Department of Population Health, University of Oxford, Old Road Campus, Headington, Oxford OX3 7LF, UK

Full list of author information is available at the end of the article
}

(c) 2016 The Author(s). Open Access This article is distributed under the terms of the Creative Commons Attribution 4.0 International License (http://creativecommons.org/licenses/by/4.0/), which permits unrestricted use, distribution, and reproduction in any medium, provided you give appropriate credit to the original author(s) and the source, provide a link to the Creative Commons license, and indicate if changes were made. The Creative Commons Public Domain Dedication waiver (http://creativecommons.org/publicdomain/zero/1.0/) applies to the data made available in this article, unless otherwise stated. 


\section{Background}

Detailed national surveillance of maternal deaths has been carried out in the UK for over 60 years, seeking reports of deaths of women during or in the 6 weeks after pregnancy from multiple sources including primary and secondary care physicians, midwives, pathologists and coroners, as well as routine death certification. It is recognised that many maternal deaths fail to be identified solely through routine death certification, particularly deaths due to medical or mental health causes when no record is made of pregnancy or recent pregnancy [1]. In addition to seeking direct notification of maternal deaths through midwives and doctors, surveillance is further enhanced through linking of data from birth registries with that from death records, and, where possible, other sources of information about recent pregnancy such as records of miscarriages or pregnancy terminations [1]. Enhanced surveillance was introduced in the UK in 2000-2 [2], and thus trends can reliably be examined for more than 10 years, without concerns that observed differences may be due to variation in case ascertainment.

The causes of maternal death are now classified internationally according to the International Classification of Diseases for Maternal Mortality (ICD-MM) [3], and are divided broadly into direct (pregnancy-related) and indirect (medical) causes. One significant change with the introduction of this guidance in 2012 was the reclassification of maternal suicide from the indirect group to the direct group. This has led to widespread concerns about the impact of this reclassification on calculated mortality rates, and therefore countries' apparent progress towards meeting both current and former targets to reduce maternal mortality $[4,5]$. It is unclear how many and which countries have formally changed to using ICD-MM and hence classify maternal suicides as direct deaths. Maternal suicides in the UK have historically always been counted, and have been classified as indirect maternal deaths. Overall, one in every eleven maternal deaths in the UK during and up to 6 weeks after pregnancy is due to a psychiatric cause; a quarter of late maternal deaths are by suicide [6]. The aim of this analysis was to examine the trends in maternal deaths in the UK over the past 10 years, and to examine the impact on the observed rates of the reclassification of maternal suicides through the use of ICD-MM.

\section{Methods}

\section{Identification of maternal deaths}

Data on maternal deaths occurring prior to 2009 were obtained from previously published reports from the UK Confidential Enquiry into Maternal Deaths [2, 7, 8]. The deaths of women from 2009 to 13 during or up to 1 year after pregnancy were identified through a variety of sources [9]. The majority were notified directly from the unit in which the maternal death occurred to Mothers and Babies: Reducing Risk through Audit and Confidential Enquiry (MBRRACE-UK), the collaboration responsible for conducting the Confidential Enquiry since 2012; some 2009 and 2010 deaths were notified to the Centre for Maternal and Child Enquiries prior to its closure in 2011 and the data subsequently passed to MBRRACE-UK. Other deaths were notified from a variety of sources such as Coroners/Procurators Fiscal or pathologists, Local Supervising Authority Midwifery Officers, media reports and members of the public.

Ascertainment of deaths was cross-checked with records from the Office for National Statistics and National Records of Scotland. Both these sources provide details of registered deaths of any women in which pregnancy, or a pregnancy-specific cause, is listed on the death certificate. In addition, maternal details in statutory birth registration records were linked to death registrations for women of reproductive age occurring over the following 12 months, in order to identify maternal deaths where pregnancy or pregnancy-specific causes were not listed on the death certificate. The deaths identified from these additional sources were then compared with the deaths reported to MBRRACE-UK and when an unreported death was identified, the hospitals where the birth and death occurred were contacted and asked to provide the medical records.

\section{Classification of underlying cause of death}

Once the complete records concerning a particular woman had been received, a pathologist and clinical epidemiologist, together with an obstetrician and/or physician as required, reviewed the anonymous records in order to classify the underlying cause of death.

\section{Definitions and statistical methods}

A maternal death was defined as per the World Health Organisation criteria as the death of a woman during or up to 6 weeks (42 days) after the end of pregnancy (whether the pregnancy ended by termination, miscarriage or a birth, or was an ectopic pregnancy) through causes associated with, or exacerbated by, pregnancy [3]. Thus for the purposes of this analysis, maternal deaths occurring between 6 weeks and 1 year after the end of pregnancy were excluded. Coincidental deaths, where the cause was considered to be unrelated to pregnancy, were excluded from this analysis, as were maternal deaths occurring more than 6 weeks after the end of pregnancy. Deaths up to and including 2013 were classified for surveillance purposes by underlying cause according to a disease-based classification used by the Enquiry for many years. For the purposes of this analysis the underlying cause was reclassified according to ICD-MM. 
Maternal mortality rates with $95 \%$ confidence intervals were calculated using national data on the number of maternities (women giving birth at or beyond 24 weeks gestation) as the denominator. Total maternities for the UK for the period 2009 to 2013 were obtained from the annually reported birth data for England and Wales [10], Scotland [11] and Northern Ireland [12]. Denominator data for other years was obtained from the previously published reports of the Confidential Enquiries into Maternal Death $[2,7,8]$.

A non-parametric test for trend across ordered groups was used to investigate the change in rolling three-yearly maternal mortality rates over time and maximum likelihood estimation was used to analyses the annual change in the rate of specific causes of death from 2009 to 13. Rate ratios with $95 \%$ CI were calculated to compare the change in rates of maternal death with $95 \%$ CI as per ICD-MM relative to the old classification system for the past 10 years. The data were analysed in STATA version 13 (Statacorp).

\section{Results}

Table 1 and Fig. 1 show rolling three-yearly maternal death rates since 2003. There was a decreasing trend in the overall maternal death rate with a $35 \%$ (95\% CI 23-46\%) decrease in the maternal death rate between 2003-05 and 2011-13 (rate ratio (RR) 0.65; $95 \% \mathrm{CI}$ 0.54-0.77 comparing 2003-5 with 2011-13; $p=0.005$ for trend over time). The direct maternal death rate calculated using the old classification decreased by more than half since 2003-05 with a RR of 0.47 (95\% CI 0.34-0.63) when comparing 2011-13 with 2003-05; $p=$ 0.005 for trend over time. Reclassification using ICDMM made little material difference to the observed trend in direct maternal death rates (Fig. 1 and Table 2), RR = 0.52 (95 \% CI 0.39-0.68) when comparing 2003-5 with 2011-13; $p=0.005$ for trend over time.
There was no statistically significant decrease in the rate of indirect maternal deaths classified using the old system (RR 0.79, $95 \%$ CI 0.63-1.00 when comparing 2011-13 with 2003-05; $p=0.278$ for trend over time). Similarly, the estimate of effect did not materially change when deaths were reclassified using ICD-MM, with no statistically significant trend over time (RR 0.77, $95 \%$ $\mathrm{CI}=0.60-0.98$ when comparing 2011-13 with 2003-5, $p=0.266$ for trend over time). Changes in the individual rates by rolling three-year period are shown in Table 3. There were no statistically significant changes in rates following reclassification.

We investigated further the decrease in the maternal death rate in 2011-13 compared to previous years in order to identify the key drivers. In addition to the decrease in direct maternal deaths, there was a statistically significant decrease in deaths due to influenza, with a $67 \%$ decrease (RR 0.33, $95 \%$ CI 0.14-0.78) when comparing 2011-13 with 2009-10; $p<0.001$ for trend over time. This is likely to be due to a lower level of influenza activity in 2011-13 compared to 2009 and 2010 when there was a major impact from pandemic 2009/AH1N1 influenza [13]. The uptake of vaccination among all pregnant women has increased by varying degrees across the UK, in England, vaccination uptake increased from $27 \%$ in 2011-12 to $40 \%$ in 2013-14; in Scotland from $41 \%$ in 2011-12 to 49 \% in 2013-14; in Northern Ireland the uptake was $58 \%$ for both time-periods, and in Wales the uptake increased from $32 \%$ in $2011-12$ to $71 \%$ in $2013-14$ [13, 14]. There was no statistically significant change in the rates of maternal death due to other causes.

\section{Deaths due to individual causes}

Maternal deaths by cause were only available on a rolling three-year basis from 2009 to 13 and are shown in Table 4. Rolling three yearly rates for individual causes are presented for three triennial reporting periods (2009-11,

Table 1 Rolling three-year average Direct and Indirect maternal mortality rates per 100,000 maternities using the old classification; UK 2003-13

\begin{tabular}{|c|c|c|c|c|c|c|c|c|c|c|}
\hline \multirow[t]{2}{*}{ 3-year period } & \multirow[t]{2}{*}{ Total UK maternities } & \multicolumn{3}{|c|}{ Direct deaths } & \multicolumn{3}{|c|}{ Indirect deaths } & \multicolumn{3}{|c|}{ Total Direct and Indirect deaths } \\
\hline & & $n$ & Rate & $95 \%$ Cl & $\mathrm{n}$ & Rate & $95 \%$ Cl & $n$ & Rate & $95 \% \mathrm{Cl}$ \\
\hline $2003-05$ & 2114004 & 132 & 6.24 & $5.26-7.41$ & 163 & 7.71 & $6.61-8.99$ & 295 & 13.95 & $12.45-15.64$ \\
\hline 2004-06 & 2165909 & 118 & 5.45 & $4.55-6.53$ & 154 & 7.11 & $6.07-8.33$ & 272 & 12.56 & $11.15-14.14$ \\
\hline 2005-07 & 2220979 & 113 & 5.09 & $4.23-6.12$ & 146 & 6.57 & $5.59-7.73$ & 259 & 11.66 & $10.32-13.17$ \\
\hline $2006-08$ & 2291493 & 107 & 4.67 & $3.86-5.64$ & 154 & 6.72 & $5.74-7.87$ & 261 & 11.39 & $10.09-12.86$ \\
\hline 2007-09 & 2331835 & 101 & 4.33 & $3.53-5.26$ & 153 & 6.56 & $5.56-7.69$ & 254 & 10.89 & $9.59-12.32$ \\
\hline 2008-10 & 2366082 & 89 & 3.76 & $3.02-4.63$ & 172 & 7.27 & $6.22-8.44$ & 261 & 11.03 & $9.73-12.45$ \\
\hline 2009-11 & 2379014 & 83 & 3.49 & $2.78-4.32$ & 170 & 7.15 & $6.11-8.30$ & 253 & 10.63 & $9.36-12.03$ \\
\hline $2010-12$ & 2401624 & 78 & 3.25 & $2.57-4.05$ & 165 & 6.87 & $5.86-8.00$ & 243 & 10.12 & 8.89-11.47 \\
\hline 2011-13 & 2373213 & 69 & 2.91 & $2.26-3.68$ & 145 & 6.11 & $5.16-7.19$ & 214 & 9.02 & $7.85-10.31$ \\
\hline
\end{tabular}

Sources: CMACE, MBRRACE-UK, Office for National Statistics, General Register Office for Scotland, Northern Ireland Statistics and Research Agency 


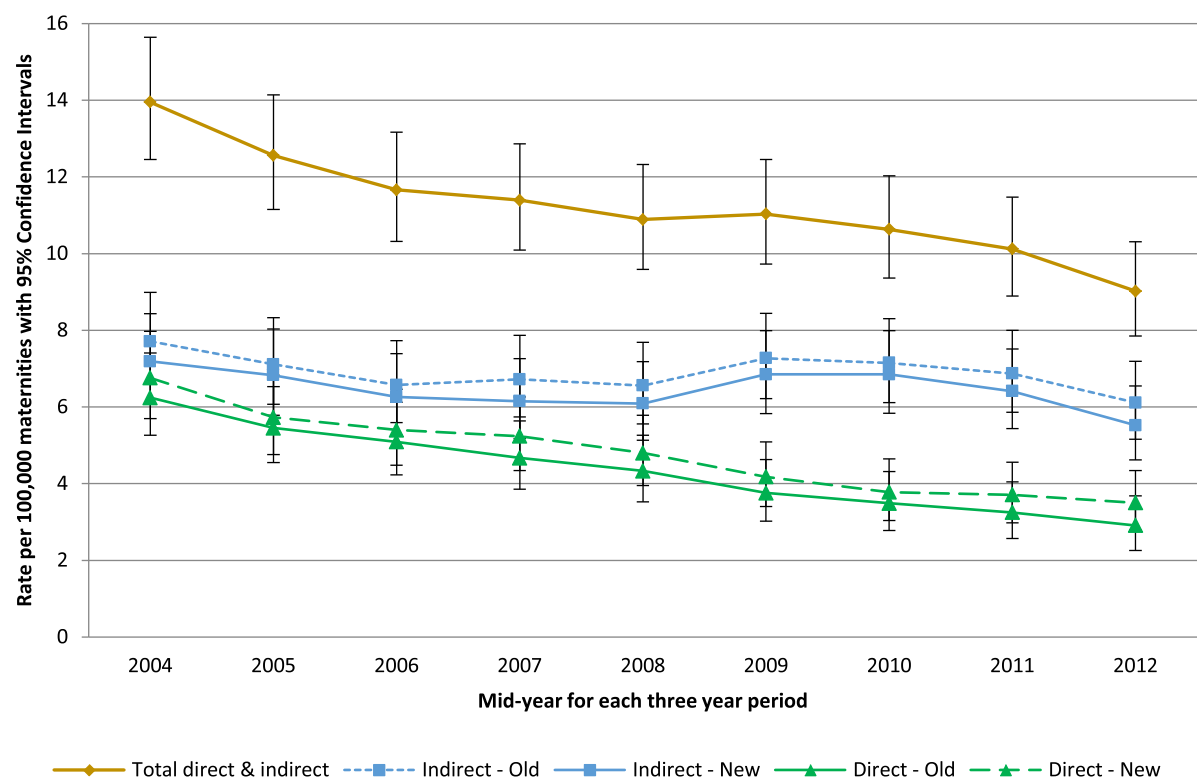

Sources: CMACE, MBRRACE-UK

Fig. 1 Direct and Indirect maternal mortality rates per 100000 maternities using different classification systems; rolling 3 year average rates 2003-2013

2010-12 and 2011-13). Table 5 presents the same data using the ICD-MM classification system. Thrombosis and thromboembolism were the leading cause of direct deaths in 2011-13 (Table 4); this did not change after the reclassification. There was no significant change in the maternal death rate from thrombosis and thromboembolism between 2009 and 2013; $p=0.481$ for trend over time. There was no significant change in the rates of direct maternal deaths due to other causes; the maternal death rate from pre-eclampsia and eclampsia is the lowest ever reported rate in the UK $(0.25$ per 100,000 maternities, 95 \% CI 0.09-0.55).

There was no statistically significant decrease in the rates of indirect maternal death over the years from 2003 to 05 to $2011-13$ and deaths due to indirect causes still remain the major proportion (68\%) of maternal deaths in the UK (Fig. 1). Cardiac disease was the largest single cause of indirect maternal deaths in 2011-13. There was no significant change in the maternal mortality rate from cardiac disease between 2009 and 2013. The rates of indirect death from other causes were also unchanged.

\section{Discussion}

\section{Main findings}

Maternal death rates in the UK declined significantly between 2003 and 13, with a $35 \%$ decrease in rate between 2003 and 5 and 2011-13. The introduction of the ICD-MM classification of maternal deaths in the UK

Table 2 Rolling three-year average Direct and Indirect maternal mortality rates per 100,000 maternities using ICD-MM; UK 2003-13

\begin{tabular}{|c|c|c|c|c|c|c|c|c|c|c|}
\hline \multirow[t]{2}{*}{ 3-year period } & \multirow[t]{2}{*}{ Total UK maternities } & \multicolumn{3}{|c|}{ Direct deaths } & \multicolumn{3}{|c|}{ Indirect deaths } & \multicolumn{3}{|c|}{ Total Direct and Indirect deaths } \\
\hline & & $n$ & Rate & $95 \% \mathrm{Cl}$ & $\mathrm{n}$ & Rate & $95 \% \mathrm{Cl}$ & $n$ & Rate & $95 \% \mathrm{Cl}$ \\
\hline $2003-05$ & 2114004 & 143 & 6.76 & $5.70-7.97$ & 152 & 7.19 & $6.09-8.43$ & 295 & 13.95 & $12.45-15.64$ \\
\hline 2004-06 & 2165909 & 124 & 5.73 & $4.76-6.83$ & 148 & 6.83 & $5.78-8.03$ & 272 & 12.56 & $11.15-14.14$ \\
\hline $2005-07$ & 2220979 & 120 & 5.40 & $4.48-6.46$ & 139 & 6.26 & $5.26-7.39$ & 259 & 11.66 & $10.32-13.17$ \\
\hline $2006-08$ & 2291493 & 120 & 5.24 & $4.34-6.26$ & 141 & 6.15 & $5.18-7.26$ & 261 & 11.39 & $10.09-12.86$ \\
\hline 2007-09 & 2331835 & 112 & 4.80 & $3.95-5.78$ & 142 & 6.09 & $5.13-7.18$ & 254 & 10.89 & $9.59-12.32$ \\
\hline 2008-10 & 2366082 & 99 & 4.18 & $3.40-5.09$ & 162 & 6.85 & $5.83-7.99$ & 261 & 11.03 & $9.73-12.45$ \\
\hline 2009-11 & 2379014 & 90 & 3.78 & $3.04-4.65$ & 163 & 6.85 & $5.84-7.99$ & 253 & 10.63 & $9.36-12.03$ \\
\hline 2010-12 & 2401624 & 89 & 3.71 & $2.98-4.56$ & 154 & 6.41 & $5.44-7.51$ & 243 & 10.12 & $8.89-11.47$ \\
\hline 2011-13 & 2373213 & 83 & 3.50 & $2.79-4.34$ & 131 & 5.52 & $4.62-6.55$ & 214 & 9.02 & $7.85-10.31$ \\
\hline
\end{tabular}

Sources: CMACE, MBRRACE-UK, Office for National Statistics, General Register Office for Scotland, Northern Ireland Statistics and Research Agency 
Table 3 Change in maternal mortality rates according to the ICD-MM classification compared with the old classification system

\begin{tabular}{|c|c|c|c|c|c|c|c|c|c|c|c|c|c|c|}
\hline \multirow{3}{*}{$\begin{array}{l}\text { 3-year } \\
\text { period }\end{array}$} & \multicolumn{7}{|c|}{ Direct deaths } & \multicolumn{7}{|c|}{ Indirect deaths } \\
\hline & \multicolumn{2}{|c|}{$\begin{array}{l}\text { Old } \\
\text { classification }\end{array}$} & \multicolumn{2}{|c|}{$\begin{array}{l}\text { New } \\
\text { classification }\end{array}$} & \multicolumn{3}{|c|}{$\begin{array}{l}\text { Change in rate compared } \\
\text { to old classification }\end{array}$} & \multicolumn{2}{|c|}{$\begin{array}{l}\text { Old } \\
\text { classification }\end{array}$} & \multicolumn{2}{|c|}{$\begin{array}{l}\text { New } \\
\text { classification }\end{array}$} & \multicolumn{3}{|c|}{$\begin{array}{l}\text { Change in rate compared } \\
\text { to old classification }\end{array}$} \\
\hline & Rate & $95 \% \mathrm{Cl}$ & Rate & $95 \% \mathrm{Cl}$ & Rate ratio & $95 \% \mathrm{Cl}$ & $p$ & Rate & $95 \% \mathrm{Cl}$ & Rate & $95 \% \mathrm{Cl}$ & Rate ratio & $95 \% \mathrm{Cl}$ & $p$-val \\
\hline $03-05$ & 6.24 & $26-$ & 6.76 & 70 & 1.08 & $0.85 \mathrm{tc}$ & 08 & 7.71 & 661 & 7.19 & 609 & 093 & 17 & 05 \\
\hline 04-06 & 5 & 33 & B & 3 & 1.05 & 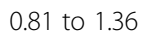 & 0.700 & 7.11 & 33 & 6.83 & 5 & 0.96 & 1.21 & 0.73 \\
\hline 05 & 5.09 & $4.23-6.12$ & 40 & 5 & 1.06 & c & 0 & 6.57 & 55 & 6.26 & 5 & 0. & 1 & 0. \\
\hline 06-08 & 4.67 & $3.86-5.64$ & 24 & 4.3 & 1.12 & .47 & 0.389 & 6.72 & 5. & 6.15 & 5. & 0.92 & .10 & 0.4 \\
\hline 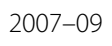 & 3 & $3.53-5.26$ & 30 & 3 & 1.11 & 0.84 to 1.47 & 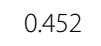 & 6 & 9 & 6.09 & 5 & 0 & 0.73 to 1.17 & 0 \\
\hline 508-10 & 3.76 & $3.02-4.63$ & 4.18 & $3.40-5.09$ & 1.11 & 0.83 & 0.467 & 7.27 & $6.22-8.44$ & 6.85 & 5.83 & 0.94 & & 0.58 \\
\hline 11 & .49 & $270 \quad 132$ & 78 & $304-165$ & 100 & $20+0110$ & 0.596 & 7.15 & $6.11-8.30$ & 6.85 & $5.84-7$ & 006 & 0 & 0.7 \\
\hline $10-12$ & 3.25 & $2.57-4.05$ & 3.71 & $2.98-4.56$ & 1.14 & 0.83 to 1.57 & 0.396 & 6.87 & $5.86-8.00$ & 6.41 & $5.44-7.51$ & 0.93 & 0.74 to 1.17 & 0.53 \\
\hline $11-13$ & 2.91 & $2.26-3.68$ & 50 & $2.79-4.34$ & 1.20 & 0.86 to 1.68 & 0.258 & 6.11 & $5.16-7.19$ & 5.52 & $4.62-6.55$ & 0.90 & 0.71 to 1.15 & 0.43 \\
\hline
\end{tabular}

had little material impact on the observed maternal mortality rates. Over the period 2003-13 there was a significantly decreasing trend in direct maternal deaths; this was observed using both the old and new, ICDMM, classification. The median relative risk increase per triennium in the direct maternal death rate was $11 \%$ when ICD-MM was used, reclassifying maternal suicides as direct maternal deaths. There was no statistically significant decrease in indirect maternal deaths during the period using either classification of maternal deaths.

Table 4 Maternal mortality rates by cause using old classification, per 100,000 maternities, 2009 to 2013

\begin{tabular}{|c|c|c|c|c|c|c|c|c|c|}
\hline \multirow[t]{2}{*}{ Cause of death } & \multicolumn{3}{|c|}{$2009-11$} & \multicolumn{3}{|c|}{$2010-12$} & \multicolumn{3}{|c|}{$2011-13$} \\
\hline & $\bar{n}$ & Rate & $95 \% \mathrm{Cl}$ & $\mathrm{n}$ & Rate & $95 \% \mathrm{Cl}$ & $\bar{n}$ & Rate & $95 \% \mathrm{Cl}$ \\
\hline All Direct and Indirect deaths & 253 & 10.63 & $9.36-12.03$ & 243 & 10.12 & $8.89-11.47$ & 214 & 9.02 & $7.85-10.31$ \\
\hline \multicolumn{10}{|l|}{ Direct deaths } \\
\hline Sepsis $^{a}$ & 15 & 0.63 & $0.35-1.04$ & 12 & 0.50 & $0.26-0.87$ & 7 & 0.29 & $0.12-0.61$ \\
\hline Pre-eclampsia and eclampsia & 10 & 0.42 & $0.20-0.77$ & 9 & 0.38 & $0.18-0.71$ & 6 & 0.25 & $0.09-0.55$ \\
\hline Thrombosis and thromboembolism & 30 & 1.26 & $0.85-1.80$ & 26 & 1.08 & $0.71-1.59$ & 24 & 1.01 & $0.65-1.5$ \\
\hline Amniotic fluid embolism & 7 & 0.29 & $0.12-0.61$ & 8 & 0.33 & $0.14-0.66$ & 10 & 0.42 & $0.20-0.78$ \\
\hline Early pregnancy deaths & 4 & 0.17 & $0.05-0.43$ & 8 & 0.33 & $0.14-0.66$ & 6 & 0.25 & $0.09-0.55$ \\
\hline Haemorrhage & 14 & 0.59 & $0.32-0.99$ & 11 & 0.46 & $0.23-0.82$ & 13 & 0.55 & $0.29-0.94$ \\
\hline Anaesthesia & 3 & 0.12 & $0.03-0.37$ & 4 & 0.17 & $0.05-0.43$ & 3 & 0.13 & $0.03-0.37$ \\
\hline All Direct & 83 & 3.49 & $2.78-4.32$ & 78 & 3.25 & $2.57-4.05$ & 69 & 2.91 & $2.26-3.68$ \\
\hline \multicolumn{10}{|l|}{ Indirect } \\
\hline Cardiac disease & 51 & 2.14 & $1.60-2.82$ & 54 & 2.25 & $1.69-2.93$ & 49 & 2.06 & $1.53-2.73$ \\
\hline Indirect Sepsis - Influenza & 27 & 1.13 & $0.75-1.65$ & 13 & 0.54 & $0.29-0.93$ & 9 & 0.38 & $0.17-0.72$ \\
\hline Indirect Sepsis - Pneumonia/ others & 16 & 0.67 & $0.38-1.09$ & 22 & 0.92 & $0.57-1.39$ & 21 & 0.89 & $0.55-1.35$ \\
\hline Other Indirect causes & 29 & 1.22 & $0.82-1.75$ & 26 & 1.08 & $0.71-1.59$ & 22 & 0.93 & $0.58-1.40$ \\
\hline Indirect neurological conditions & 30 & 1.26 & $0.85-1.80$ & 31 & 1.29 & $0.88-1.83$ & 24 & 1.01 & $0.65-1.5$ \\
\hline Psychiatric causes & 13 & 0.55 & $0.29-0.93$ & 16 & 0.67 & $0.38-1.08$ & 19 & 0.80 & $0.48-1.25$ \\
\hline Indirect malignancies & 4 & 0.17 & $0.05-0.45$ & 3 & 0.13 & $0.03-0.37$ & 1 & 0.04 & $0.001-0.24$ \\
\hline All Indirect & 170 & 7.15 & $6.11-8.30$ & 165 & 6.87 & $5.86-8.00$ & 145 & 6.11 & $5.16-7.19$ \\
\hline Coincidental & 23 & 0.98 & $0.61-1.45$ & 26 & 1.08 & $0.71-1.59$ & 26 & 1.10 & $0.72-1.61$ \\
\hline
\end{tabular}

Source: MBRRACE-UK, Office for National Statistics, General Register Office for Scotland, Northern Ireland Statistics and Research Agency

${ }^{a}$ Genital tract sepsis deaths only, including early pregnancy deaths as the result of genital tract sepsis. Other deaths from infectious causes are classified under indirect causes 
Table 5 Maternal mortality rates by cause using ICD-MM, per 100,000 maternities, 2009 to 2013

\begin{tabular}{|c|c|c|c|c|c|c|c|c|c|}
\hline \multirow[t]{2}{*}{ Cause of death } & \multicolumn{3}{|c|}{$2009-11$} & \multicolumn{3}{|c|}{$2010-12$} & \multicolumn{3}{|c|}{$2011-13$} \\
\hline & $n$ & Rate & $95 \% \mathrm{Cl}$ & $n$ & Rate & $95 \% \mathrm{Cl}$ & $\mathrm{n}$ & Rate & $95 \% \mathrm{Cl}$ \\
\hline \multicolumn{10}{|l|}{ Direct causes } \\
\hline Group 1: Pregnancy with abortive outcome & 4 & 0.17 & $0.05-0.43$ & 8 & 0.33 & $0.14-0.66$ & 6 & 0.25 & $0.09-0.55$ \\
\hline Group 2: Hypertensive disorders & 10 & 0.42 & $0.20-0.77$ & 9 & 0.38 & $0.18-0.71$ & 6 & 0.25 & $0.09-0.55$ \\
\hline Group 3: Obstetric Haemorrhage & 14 & 0.59 & $0.32-0.99$ & 11 & 0.46 & $0.23-0.82$ & 13 & 0.55 & $0.29-0.94$ \\
\hline Group 4: Pregnancy-related infection & 16 & 0.67 & $0.38-1.09$ & 13 & 0.54 & $0.29-0.93$ & 8 & 0.34 & $0.15-0.66$ \\
\hline Group 5: Other obstetric complications & 43 & 1.81 & $1.31-2.43$ & 44 & 1.83 & $1.33-2.46$ & 47 & 1.98 & $1.46-2.63$ \\
\hline Group 6: Unanticipated complications of management & 3 & 0.12 & $0.03-0.37$ & 4 & 0.17 & $0.05-0.43$ & 3 & 0.13 & $0.03-0.37$ \\
\hline \multicolumn{10}{|l|}{ Indirect causes } \\
\hline Group 7: Non-obstetric complications & 163 & 6.85 & $5.84-7.99$ & 154 & 6.41 & $5.44-7.51$ & 131 & 5.52 & $4.62-6.55$ \\
\hline Group 8: Unknown/undetermined & 0 & 0 & - & 0 & 0 & - & 0 & 0 & - \\
\hline \multicolumn{10}{|l|}{ Coincidental causes } \\
\hline Group 9: Coincidental causes & 23 & 0.98 & $0.61-1.45$ & 26 & 1.08 & $0.71-1.59$ & 26 & 1.10 & $0.72-1.61$ \\
\hline
\end{tabular}

Source: MBRRACE-UK, Office for National Statistics, General Register Office for Scotland, Northern Ireland Statistics and Research Agency

Indirect causes of death still represent the majority of maternal deaths in the UK (62 \%) using the ICD-MM classification.

\section{Strengths and limitations}

This study used data from a long-standing comprehensive programme of national surveillance and confidential enquiry into maternal deaths. There is a high ascertainment of maternal deaths and a comprehensive review of the underlying cause of each death, which enabled straightforward reclassification using ICD-MM. The UK has no national records through which to link reports of miscarriages to deaths of women of reproductive age, and thus it is possible that some deaths following early pregnancy loss were not ascertained where the cause of death was not a direct pregnancy complication, since this relies on the clinicians certifying the death noting recent pregnancy on the death certificate. However, this is unlikely to have affected the observed trends, and would not affect the evaluation of the impact of reclassification.

\section{Comparison with other studies}

Very few published studies have examined the impact of reclassifying deaths using ICD-MM; we were not able to identify any from high resource settings. Other studies from low and middle-income countries have reported a varying impact of reclassifying deaths using ICD-MM. A regional study from Sri Lanka reported a 57 \% increase in the number of deaths classified as maternal deaths when classified using ICD-MM, from 53 to 83 , principally due to reclassification of 18 maternal suicides which had previously been classified as coincidental [15]. In contrast, a study in five sub-Saharan African countries, which reanalysed data on over 4000 maternal deaths, mostly from the South African Confidential Enquiry into Maternal Deaths, makes no mention of maternal suicides [16]. It is unclear whether this is because maternal suicides were not included in the datasets (as they were not previously classified as maternal deaths), or whether the reclassification of suicides had little impact in settings with high rates of maternal mortality, particularly HIV related. Similarly, a study from Malawi introducing the ICD-MM classification to maternal death reviews included only one death in the group 'other obstetric complications', out of 53 deaths reviewed [17]. It is not reported whether this was a maternal suicide, however, it is unlikely that suicides were included as the deaths reviewed were only those which occurred in hospitals.

This failure to discuss suicides is perhaps symptomatic of a widespread reluctance to acknowledge maternal mental health problems as an important cause of maternal death. A 2014 systematic review aiming to assess the contribution of suicide to pregnancy-related mortality in low and middle-income countries estimated that $1.7 \%$ of pregnancy-related deaths could be attributed to suicide, but notes that the study may have underestimated suicide deaths because of the absence of recognition and inclusion of these causes in eligible studies [18]. The most recent report from the UK Confidential Enquiry into Maternal Death conducted reviews of the deaths of over 100 women who died by suicide; maternal suicides were the cause of almost a quarter of the UK's late maternal deaths (occurring between 6 weeks and 1 year after the end of pregnancy) [6]. The reviewers noted that many women had symptoms for weeks or months before their eventual deaths, and that there were multiple opportunities to improve care, which may have prevented their deaths. These opportunities for improving care were irrespective of their mental health diagnosis, that is, they were not limited 
solely to women with postnatal depression or puerperal psychosis [6]. This supports the approach taken in ICDMM to include all suicides of women during or after pregnancy in the classification of direct maternal deaths, in order to render the invisible visible and hence begin to improve maternal mental health care in the same way as actions are taking place to improve intrapartum care.

It is important to note that the UK has been including maternal suicides in their Confidential Enquiries into Maternal Deaths for many years, and there is evidence that the rate of maternal death from suicide has decreased as a consequence. It is therefore possible that the impact of the ICD-MM reclassification in the UK was less than if this had not been the case, as awareness of maternal suicide has already been raised and actions to prevent suicides put in place. Nonetheless, this illustrates the importance of both the WHO Maternal Death Surveillance and Response (MDSR) programme [19] and the 'Beyond the Numbers' approach [1]. Counting maternal deaths is important, but more important is reviewing the maternal deaths to identify not just the 'what' but the 'why' - identifying actions to improve care, implementing those actions and monitoring the impact on maternal deaths.

\section{Conclusions}

There has been a statistically significant decrease of $35 \%$ in the maternal death rate in the UK over the period 2003-2013. However, it is important to note that, even in a high resource country with a long history of maternal deaths surveillance and review, the Millennium Development Goal target of a $75 \%$ reduction in maternal deaths between 1990 and 2015 is unlikely to be reached, thus there is no room for complacency. In a country where awareness of maternal suicide was raised several years ago, and suicides of women during or in the 6 weeks after the end of pregnancy have long been counted as indirect maternal deaths the impact of reclassifying maternal suicides as direct maternal deaths was minimal. However, such reclassification raises awareness of maternal suicides and hence is the first step to actions to prevent women dying in the future. Recognising and acknowledging these women's deaths is more important than concerns over the impact reclassification using ICD-MM might have on reported maternal death rates.

\section{Abbreviations \\ ICD-MM, International classification of diseases for maternal mortality; MBRRACE-UK, Mothers and Babies: reducing risk through audit and confidential enquiry in the UK; RR, rate ratio}

\section{Funding}

MK is funded by an NIHR Research Professorship.

The Maternal, Newborn and Infant Clinical Outcome Review Programme, delivered by MBRRACE-UK, is commissioned by the Healthcare Quality Improvement Partnership (HQIP) on behalf of NHS England, NHS Wales, the Health and Social Care Division of the Scottish government, The Department of Health, Social Services and Public Safety (DHSSPS), Northern Ireland, the States of Jersey, Guernsey and the Isle of Man.

The views expressed in this publication are those of the author(s) and not necessarily those of the NHS, the NIHR, the Department of Health or other funders

The funding sources had no role in the design of the study and collection, analysis, and interpretation of data or in writing the manuscript.

\section{Availability of data and materials}

MBRRACE-UK data are available on application to the Healthcare Quality Improvement Partnership.

\section{Authors' contributions}

MK conceived and designed the study, supervised the analysis, wrote the first draft of the paper and approved the final manuscript. MN carried out the analysis, assisted with the writing of the paper and approved the final manuscript. PB assisted with the design of the study, assisted with the writing of the paper and approved the final manuscript. SK assisted with the design of the study, assisted with the writing of the paper and approved the final manuscript. JN assisted with the design of the study, assisted with the writing of the paper and approved the final manuscript. JS assisted with the design of the study, assisted with the writing of the paper and approved the final manuscript. DT assisted with the design of the study, assisted with the writing of the paper and approved the final manuscript. JJK assisted with the design of the study, assisted with the writing of the paper and approved the final manuscript.

\section{Competing interests}

The authors declare that they have no competing interests.

\section{Ethics approval and consent to participate}

MBRRACE-UK data are collected in England and Wales with the approval of the Secretary of State for Health obtained by application to the Confidentiality Advisory Group of the Health Research Authority (reference 15/CAG/0119). The data are collected in Scotland with the approval of NHS Scotland Caldicott Guardian and the NHS National Services Scotland Privacy Advisory Committee. Northern Ireland data are collected via the Northern Ireland Maternal and Child Health Office, Public Health Agency. No further ethics committee approvals were required for this analysis, which was carried out as part of the MBRRACE-UK programme of work.

\section{Consent for publication}

Not applicable.

\section{Author details}

${ }^{1}$ National Perinatal Epidemiology Unit, Nuffield Department of Population Health, University of Oxford, Old Road Campus, Headington, Oxford OX3 7LF, UK. ${ }^{2}$ Institute for Women's Health UCL, Medical School Building, 74 Huntley Street, London WC1E 6AU, UK. ${ }^{3}$ School of Health and Population Sciences, Edgbaston Campus, University of Birmingham, Edgbaston B15 2TT, UK. ${ }^{4}$ Department of Women's \& Children's Health, Institute of Translational Medicine, University of Liverpool and Centre for Women's Health Research, Liverpool Women's Hospital, Crown Street, Liverpool L8 7SS, UK. ${ }^{5}$ Bradford Teaching Hospitals NHS Foundation Trust, Duckworth Lane, Bradford BD9 6RJ, UK.

Received: 14 October 2015 Accepted: 12 July 2016 Published online: 20 July 2016

\section{References}

1. World Health Organisation. Beyond the numbers: reviewing maternal deaths and complications to make pregnancy safer. Geneva: World Health Organisation; 2004.

2. Lewis G, editor. Why mothers die 2000-2002. London: Royal College of Obstetricians and Gynaecologists; 2004.

3. The WHO Application of ICD-10 to deaths during pregnancy, childbirth and the puerperium: ICD-MM [http://apps.who.int/iris/bitstream/10665/70929/1/ 9789241548458_eng.pdf?ua=1]. Accessed 07 Oct 2015.

4. Millennium Development Goal 5: Improve maternal health [http://www.un.org/millenniumgoals/maternal.shtml]. Accessed 07 Oct 2015. 
5. Sustainable Development Goals [https://sustainabledevelopment.un.org/ ?menu=1300]. Accessed 07 Oct 2015.

6. On behalf of MBRRACE-UK. In: Knight MNM, Tuffnell D, Kenyon S, Shakespeare J, Gray R, Kurinczuk JJ, editors. Saving lives, improving Mothers' care - surveillance of maternal deaths in the UK 2011-13 and lessons learned to inform maternity care from the UK and Ireland confidential enquiries into maternal deaths and morbidity 2009-13. Oxford: National Perinatal Epidemiology Unit, University of Oxford; 2015.

7. Lewis GE, editor. The confidential enquiry into maternal and child health (CEMACH). saving mothers lives: reviewing maternal deaths to make childhood safer - 2003-2005. London: CEMACH; 2007.

8. Lewis G, Cantwell R, Clutton-Brock T, Cooper G, Dawson A, Drife J, Garrod D, Harper A, Hulbert D, Lucas S, et al. Saving Mothers' lives: reviewing maternal deaths to make motherhood safer: 2006-2008. The eighth report of the confidential enquiries into maternal deaths in the United Kingdom. BJOG. 2011;118(1):1-203.

9. Kurinczuk JJ, Draper ES, Field DJ, Bevan C, Brocklehurst P, Gray R, Kenyon S, Manktelow BN, Neilson JP, Redshaw M, et al. Experiences with maternal and perinatal death reviews in the UK-the MBRRACE-UK programme. BJOG. 2014;121:41-6.

10. Birth summary tables, England and Wales [http://www.ons.gov.uk/ons/rel/ vsob1/birth-summary-tables-england-and-wales/index.html]. Accessed 07 Oct 2015.

11. Vital Events Reference Tables [http://www.nrscotland.gov.uk/statistics-anddata/statistics/statistics-by-theme/vital-events/vital-events-reference-tables] Accessed 07 Oct 2015

12. Registrar General Annual Reports [http://www.nisra.gov.uk/demography/ default.asp22.htm]. Accessed 07 Oct 2015

13. Public Health England. Surveillance of influenza and other respiratory viruses in the United Kingdom: winter 2013/14. London: Public Health England; 2014.

14. Public Health England. Surveillance of influenza and other respiratory viruses, including novel respiratory viruses, in the United Kingdom: winter 2012/13. London: Public Health England; 2013

15. Agampodi S, Wickramage K, Agampodi T, Thennakoon U, Jayathilaka N, Karunarathna D, Alagiyawanna S. Maternal mortality revisited: the application of the new ICD-MM classification system in reference to maternal deaths in Sri Lanka. Reprod Health. 2014;11(1):17.

16. Ameh CA, Adegoke A, Pattinson RC, van den Broek N. Using the new ICD-MM classification system for attribution of cause of maternal death-a pilot study. BJOG. 2014;121 Suppl 4:32-40.

17. Owolabi H, Ameh CA, Bar-Zeev S, Adaji S, Kachale F, van den Broek N. Establishing cause of maternal death in Malawi via facility-based review and application of the ICD-MM classification. BJOG. 2014;121 Suppl 4:95-101.

18. Fuhr D, Calvert C, Ronsmans C, Chandra P, Sikander S, De Silva M, Patel V. Contribution of suicide and injuries to pregnancy-related mortality in low-income and middle-income countries: a systematic review and meta-analysis. Lancet Psychiatry. 2014;1(3):213-25.

19. Maternal Death Surveillance and Response Technical Guidance [ http://www.unfpa.org/sites/default/files/pub-pdf/Maternal_Death_ Surveillance_and_Response_0.pdf]. Accessed 07 Oct 2015.

\section{Submit your next manuscript to BioMed Central and we will help you at every step:}

- We accept pre-submission inquiries

- Our selector tool helps you to find the most relevant journal

- We provide round the clock customer support

- Convenient online submission

- Thorough peer review

- Inclusion in PubMed and all major indexing services

- Maximum visibility for your research

Submit your manuscript at www.biomedcentral.com/submit
Biomed Central 